(20.3\%). The incidence of MSDs in upper back, finger, elbow, ankle and hip were 8.4\%, 7.94\%, 7.94\%, 4.34\%, 4.14\%, respectively. Thirty-six variables were found significantly associated with MSDs. Eight out of 36 were identified as risk factors, including female $(O R=1.63)$, age older than 50 years $(O R=1.64)$, working on greenhouse long than 20 years $(O R=2.24)$, daily work over 10 hours $(O R=1.32)$, frequent push or pull with power ranged from 5 to $20 \mathrm{~kg}(O R=1.56)$, elevating heavy objects in uncomfortable position $(O R=1.57)$, bending down in work $(O R=1.84)$, neck at layback for long time in work $(O R=1.31)$. While, use of vibrating tools in work was a protective factor $(O R=0.58)$.

Conclusions The incidence of MSDs is high in the farmers working on greenhouse vegetable. The findings of this study on the correlates of MSDs could inform future development of more specific and efficacious interventions.

\section{MOTHERS AND FATHERS PERCEPTIONS OF INJURY RISKS TO YOUTH WORKING ON FAMILY FARMS}

Zolinda Stoneman, Hamida Jinnah, , Rebecca Brightwell. University of Georgia, USA

\subsection{6/injuryprev-2016-042156.768}

Background Youth live in the agricultural workplace and are at risk of injury and death on the family farm. Fathers usually oversee the most dangerous youth farm work, namely work around large equipment. Less is known about the safety roles and beliefs of mothers. This study examined differences between mothers and fathers in their work and family roles on the family farm, as well as differences in risk-taking, safety perceptions and knowledge, and perceptions of youth injury risk.

Methods Participants were 248 farm parents (124 married couples) with a youth aged 9-19 yrs. Families lived on farms growing row crops in the Southeastern U.S. Mothers and fathers completed study questionnaires.

Results Mothers were less likely than fathers to operate tractors and large equipment, had lower safety self-efficacy, less confidence and perceptions of control related to keeping their youth safe, less safety training, and less knowledge about farm safety. As compared to fathers, mothers believed that youth should be older before being allowed to work with and operate farm equipment. Unexpectedly, mothers perceived less injury risk to youth than did fathers. Fathers were greater risk-takers than were mothers. For both mothers and fathers, higher risk-taking was associated with less perceived youth injury risk. When asked about decisionmaking related to youth's use of farm equipment, mothers often deferred to fathers.

Conclusions Study findings suggest that on family farms growing row crops in the Southeastern U.S., mothers perceive less injury risk to their youth than do fathers. Gendered labour patterns and limited access to agricultural networks and training constrain women's knowledge about farm safety, especially related to large equipment. These factors may compromise the ability of some women to work jointly with their husbands to keep their youth safe. There is a need for communities to provide farm safety education designed for women, as well as men.

\section{INDENTIFYING DEFICIENCIES IN STABILITY, DYNAMIC HANDLING AND ROLLOVER CRASHWORTHINESS OF QUAD BIKES}

${ }^{1}$ Raphael Grzebieta, ${ }^{1}$ George Rechnitzer, ${ }^{1,2}$ Keith Simmons, ${ }^{1}$ David Hicks, ${ }^{3}$ Drew Sherry, ${ }^{3}$ Ross Dal Nevo, ${ }^{4}$ Andrew Mclntosh. ${ }^{1}$ Transport and Road Safety (TARS) Research Centre, University of New South Wales, Australia; ${ }^{2}$ KND Consulting Pty Ltd, Australia; ${ }^{3}$ Roads and Maritime Services, Crashlab, Australia; ${ }^{4}$ McIntosh Consultancy and Research

\subsection{6/injuryprev-2016-042156.769}

Background Currently, in Australia there are around 270,000 quad bikes (ATVs) and Side by Side Vehicles (SSVs) in use, an estimated 80,000 Quad bikes and SSVs in New Zealand, and an estimated 10 million Quad bikes and SSVs in the USA. Analysis of Australian Coronial data from 2001 to 2012 identified around 141 fatalities involving quad-bikes and SSVs. In comparison 2,718 quad-bike fatalities occurred in the US in the years 2000 to 2010. Fatality data indicates that rollover, pinned entrapment and asphyxiation are the major casual factors in farm place deaths related to quad-bikes. As a result, the authors critically evaluated quad bike static stability, dynamic handling and rollover crashworthiness to identify engineering design deficiencies and possible countermeasures to reduce rollover injury risk.

Methods A major three year project comprised of over 1000 tests on a selection of 17 vehicles consisting of 8 quad bikes, 3 recreational quad bikes, 5 SSVs and a modified prototype quad bike. Testing was carried out at the NSW state government's Crashlab testing facility, consisting of ststic stability, dynamic handling and rollover crashworthiness tests.

Results Results from all the test program are presented, with links provided to the extensive project and Crashlab test reports. Conclusions Deficiencies in the stability and handling of quad bikes which significantly increased the rollover risk with consequent increased risk of severe injury and death in the farming environment were identified and quantified. For the first time, the comparison of quad bikes with SSVs identified the superior static stability, dynamic handling, minimal disturbance of steering when traversing a bump, and rollover crashworthiness of SSVs. Quad bikes are not the best choice for workplace and farm vehicles but rather well designed SSVs, in general, are the more appropriate 'fit for purpose' vehicle choice.

\section{AN EVALUATION OF THE UTILITY OF VARIOUS DATA SOURCES FOR OCCUPATIONAL INJURY SURVEILLANCE}

${ }^{1}$ Rafael Consunii, ${ }^{2}$ Amber Mehmood, ${ }^{1}$ Furqan Irfan, ${ }^{1}$ Rania Abdelhamid, ${ }^{1}$ Ruben Peralta, ${ }^{1}$ Ayman El-Menyar, ${ }^{2}$ Katharine A Allen, ${ }^{1}$ Shahnaz Malik, ${ }^{1}$ Hassan Al-Thani, ${ }^{2}$ Adnan Hyder ${ }^{1}$ Hamad Medical Corporation, Qatar; ${ }^{2}$ Johns Hopkins Bloomberg School of Public Health, U. S.A

\subsection{6/injuryprev-2016-042156.770}

Background Work-related injuries (WRIs) have been identified as a public health priority in Qatar. At present data on WRIs is collected by diverse governmental and non-governmental agencies. This study evaluates the utility of various data sources for occupational injury surveillance based on international reporting standards of the International Labour Organisation [ILO], Occupational Safety and Health Administration [OSHA] and International Classification of Diseases 10 [ICD-10].

Methods Stakeholder meetings with agencies working for the welfare and health of workers in Qatar were held to assess the existence and availability of data sources and develop consensus on the definition of essential elements related to WRIs 